Original paper

\title{
VigiFlood: Evaluating the Impact of a Change of Perspective on Flood Vigilance
}

\section{Carole Adam ${ }^{1}$}

Received: 20/02/2020 / Accepted: 10/09/2020 / Published online: 27/10/2020

\begin{abstract}
Emergency managers receive communication training about the importance of being 'first, right and credible', and taking into account the psychology of their audience and their particular reasoning under stress and risk. But we believe that citizens should be similarly trained about how to deal with risk communication. In particular, such messages necessarily carry a part of uncertainty since most natural risks are difficult to accurately forecast ahead of time. Yet, citizens should keep trusting the emergency communicators even after they made forecasting errors in the past.
\end{abstract}

We have designed and implemented a serious game called Vigiflood, based on a real case study of flash floods hitting the South West of France in October 2018. In this game, the user changes perspective by taking the role of an emergency communicator, having to set the level of vigilance to alert the population, based on uncertain clues. Our hypothesis is that this change of perspective can improve the player's awareness of flood risk, and response to future flood vigilance announcements.

We evaluated this game through an online survey where people were asked to answer a questionnaire about flood risk awareness and behavioural intentions before and after playing the game, in order to assess its impact. The results are encouraging, showing improved risk awareness, protective intentions, vigilance, and trust after playing. However, it also suggests that the current "game design" is still poor and unable to engage the general public, in particular school students. Future research will therefore address this issue.

Key words: crisis communication, trust, subjective risk, agent-based model, serious game

\footnotetext{
${ }^{1}$ Univ. Grenoble Alpes, LIG, Grenoble, F-38000 France. Email: Carole.Adam@imag.fr
} 


\section{INTRODUCTION}

\subsection{Context}

Nowadays, our societies are exposed to increasingly frequent natural disasters (CRED Center for Research on the Epidemiology of Disasters n.d.) that cause more and more victims and economical losses as the density of population increases (Svetlana et al. 2015; Duan et al. 2016). Floods in particular are expected to happen more and more often in some parts of the world due to the global warming (Roudier et al. 2016; Kerr 2007; Schiermeier 2011). (Attansey 2012) found that individuals might get desensitized after multiple occurrences of floods, and that communication has a key role to play to maintain vigilance. Unfortunately, meteorological events such as flash floods are hard to predict, highly undeterministic, depending on many factors (Duan, He, Takara, et al. 2014). For instance, thunderstorms can be predicted but it is hard to know in advance their exact trajectory and the area that will be affected by intense rain or subsequent floods. As a result, the weather information and alerts communicated to the population by meteorological services are inherently probabilistic and uncertain. Forecasts are usually accompanied by a trust index indicating how certain they are, but people have trouble interpreting probabilistic or statistical messages (Eiser 1998), and they underestimate rare or extreme events (Burningham et al. 2008). Yet it is crucial to warn people so they can take protective actions soon enough (Grothmann and Reusswig 2006), even though these precautions might end up unnecessary.

Consequently, weather forecasters are faced with a dilemma about when to raise an early warning (Pearson 2012; Geleta 2013): either wait to have more certainty before announcing a weather event, at the risk of missing it or announcing it too late, possibly causing victims; or announce a probable event before being sure, based on insufficient or unreliable clues, at the risk of over-alerting the population. This second option is generally considered as more acceptable, as it does not cause immediate victims. For instance, Météo France communicates a ratio of about $15 \%$ of over-alerting, but only 2-3\% of under-alerting (Le Monde 2018). However, alerts should be used with precaution to avoid panic (Arru et al. 2019). Besides, the population might lose trust after several over-alerts, that they might consider as "false alerts". This would result in not trusting subsequent alerts even when justified. This is for example what happened in recent floods in the South West of France in October 2018 (Libération-AFP 2018; Gominet 2018).

\subsection{Problematic}

Efficient crisis communication is very challenging, and the population's actual reaction does not always match what is recommended and expected by the authorities (Rhodes 2014), with potentially disastrous consequences (refusal to evacuate, lack of preparation, etc). This gap can have many explanations (Parker, Priest, and Tapsell 2009): a lack of understanding of instructions, mistrust in the authority and their messages, or not knowing which actions to take exactly; social attachment (making gathering with one's family more important than saving 
one's life (Bañgate et al. 2017)); cognitive biases (Murata et al. 2015; Arnaud et al. 2017); or a lack of personalization of communication (Adam and Gaudou 2016).

There is clearly a misunderstanding here, where the population and media believe that the weather forecasters do a poor job (Libération-AFP 2018), without realizing the underlying difficulties (Gominet 2018); and the weather forecasters do not understand why the population will not listen to the warnings (Rhodes 2014). In such a situation, role-playing games have shown their interest for changing people's perspective and letting them understand other points of view and gain "enhanced awareness of other perspectives" (Bowman 2014). As also suggested by Shubik (1971), "in many of the uses of gaming seeing the other individual's point of view by role playing his position appears to be of value" (p. 6).

\subsection{Proposition / approach}

Our goal here is therefore to propose such a role-playing experience to improve communication between weather forecasters and the population of flood-prone areas. Concretely, we propose VigiFlood, a serious game where the player has to take on the role of an emergency communicator setting the level of vigilance based on uncertain weather forecast; they get feedback about the effect of their actions on the simulated population (trust, evacuation decision). We have implemented a first prototype of this serious game (Adam and Andonoff 2019), but improvements are still ongoing. The game is based on a multi-agent model grounded on psychological and sociological theories, and on real hydrological and meteorological data from a flood-prone area in the South West of France.

In this paper, we want to verify if the change of perspective induced by Vigiflood does let the players gain awareness about the difficulty of flood risk prediction and communication, and leads to a subsequent change in their behaviour. We have therefore designed an online questionnaire to measure the objective impact of this change of perspective on the players' awareness of the challenges of flood risk communication. Concretely, we measured several indicators, both before and after playing the role of a weather forecaster: the players' risk awareness, trust, vigilance, consciousness of their own responsibility for action, and protective actions intentions. The first results described here show an improvement in these values, suggesting that such a serious game has an interest in raising awareness in the population and improving communication and prevention in case of floods.

In order for the final serious game to have an actual impact, it needs to be played by the population. In line with participatory research (Becu 2020), this is easier to achieve by involving the target users early on. This is why our survey also integrates subjective questions about the responders' opinion on the subjective interest and playability of the serious game, and their will to see it implemented in their town or in schools. With no surprise, our first prototype is not engaging enough, but people find it really interesting and are willing to see such a tool implemented on the field. This is encouraging us to pursue research on this path, and ongoing work is now directed towards improving the game design and immersion of our first prototype. 


\subsection{Outline}

This paper is structured as follows. Section 2 discusses the use of agent-based simulation and serious games for crisis management. Section 3 then provides the reader with an overview of useful research in the social sciences about crisis communication, trust, or risk evaluation, that will serve as the basis for our model. Section 4 presents some context about flash floods, the French vigilance system, and our case study. Section 5 describes our serious game, Vigiflood, and its underlying agent-based model. Section 6 is the core contribution and presents our evaluation of Vigiflood, the questionnaire design, its ethical validation, and the results obtained from an analysis of 80 answers gathered during the month of June 2019. Finally, Section 7 concludes and discusses future prospects of this research.

\section{SIMULATIONS AND SERIOUS GAMES}

In this paper we want to provide a solution to improve communication, vigilance and trust around flash flood risk in flood-prone areas. Our approach is to provide a computerized serious game offering a change of perspective to players from the population. This serious game is based on an agent-based simulation of the reaction of the population to the flood vigilance messages received. This section defines the concepts and reviews existing research in this field.

\subsection{Agent-based simulations}

Agent-based social simulations (Bonabeau 2002) are a computer science approach modelling the behaviour and interactions of autonomous entities called agents, each representing a human individual, in order to study the resulting behaviour of the global society. It is a very useful tool to understand the behaviour of a complex system as emerging from the individual behaviours of its members, for instance how a crowd evacuates from a building, or how traffic jams appear on a busy road.

Axelrod (1997) defines seven purposes of simulations, including prediction (simulate a system very realistically to predict its future behaviour, e.g. meteorology), training (provide a believable interactive environment to rehearse actions, e.g. flight simulator), or education (let the user learn by trial-and-error in a virtual world). Predictive simulations require a high degree of realism to lay valid predictions, while training and education simulations can be simpler and less realistic (they "need not be rich enough to suggest a complete real or imaginary world"). Besides, Axelrod also claims that "the simpler the model, the easier it may be to discover and understand the subtle effects of its hypothesized mechanisms"; educational simulations are therefore often quite simple.

Computer simulations allow to explore completely controlled scenarios, to repeat them as many times as necessary, at no cost and with no stakes, in order to gain simulated experience. As a result of such advantages, computer simulations have often been used in crisis 
management (Murakami et al. 2002) for various purposes. For instance (Yang et al. 2018) provide a very realistic model based on field data, to predict the impact of early warnings on population behaviour in terms of reducing material losses from floods. Others focus on realistically modelling the physical flood phenomenon in order to support decisions regarding early warnings for tsunamis (Friedemann et al. 2011), based on data from multiple sensors (Behrens et al. 2008).

Other simulations focus on communication, but not necessarily during floods. (Arru et al. 2019) study if the population should be alerted or not of an ongoing crisis (e.g. terrorist attack), depending on the anticipation of their potential reaction (e.g. crowd panic), which is based on a psychological model. Since events considered are ongoing, they do not deal with false alarms and their potential impact on long-term trust. (Adam and Dugdale 2018) study the propagation of awareness in the Australian population after a bushfires warning, depending on its channel and (familiar vs unfamiliar) source. Since they consider a single event, they do not deal with long-term dynamics of trust over multiple (right and wrong) alerts. (Haer et al. 2016) use an agent-based model to study the effectiveness of flood risk communication strategies, showing that it is important to communicate not only about the risk but also about how to cope with it; they also find that this impact propagates through social networks.

Computer simulations are often designed and implemented by computer scientists, and then used on the field. Participatory simulation (Becu 2020) is an approach where the stakeholders or users are invited to participate in the entire process of designing, modelling and simulating a given problem. This co-construction lets participants share knowledge and points of view. This approach is very adapted to environmental stakes or urban planning, to accompany discussion between scientists, deciders and citizens.

\subsection{Serious games}

Clark Abt coined the term of "serious games" in 1970 (Abt 1970; Djaouti et al. 2011). This American researcher worked on computer simulation games for military training during the cold war, and supported the potential of games for serious applications, in particular for education. He defines serious games as games that "have an explicit and carefully thought-out educational purpose and are not intended to be played primarily for amusement" but insists that this does not and should not prevent serious games from being entertaining. He reviewed many examples of such serious games on various formats: board games, card games, outdoor games, or computer games, which we focus on here.

An important advantage of serious games compared to more traditional educative approaches is to favour the learners' engagement (Garris et al. 2002; Boyle et al. 2016). For instance (Burke et al. 2009) have obtained encouraging results when using video games to solve disengagement problems and motivate patients to stick with intensive and repetitive rehabilitation exercises. Many serious games are specifically targeted at children. It is argued that children are often more enthusiastic, motivated to learn, and receptive to new ideas (Izadkhah and Hosseini 2005) (p. 142). Besides, they are a good channel to reach (and 
convince) their parents, and spread the ideas to the wider society (Barreto 2014) (p. 19). (Fitzgerald et al. 2000) (p. 1) confirm that it is better to develop an active (rather than fatalistic) mind-set about disaster risks at an "early age", and a culture of prevention takes time to form. However, engaging children requires engaging their teachers first.

In crisis management and disaster prevention, serious games are often used to teach appropriate behaviours or to train deciders (see (Di Loreto et al. 2012) for a review). Indeed, they are a good way to make the population aware of their responsibilities, and to promote their active participation, compared to more traditional or vertical approaches of imposing knowledge (Yamori 2012). For instance, these authors have developed Crossroad, a card game for tsunami prevention in Japan where the players have to find their own viable solutions to social dilemmas, rather than accepting externally prescribed solutions. (Horita et al. 2014) also study the use of gamification to improve community knowledge, awareness and resilience in case of disasters; they have developed an online platform to foster collaboration.

Some serious games focus on communication. For instance (Adam and Bailly 2019) proposed a serious game for trying various communication strategies to alert the population (focused vs wide targeting, information vs recommendations) before and during bushfires in Australia, but they do not deal with the timing of alerts nor the impact on trust. Indeed, they report no habituation phenomenon to fire alerts, which could be due to the easier predictability of fires compared to flash floods, or to normative and cultural differences.

Several serious games exist that address floods, with different targets and different formats. Anycare is a table-top role-playing game to involve stakeholders (Terti et al. 2019), and requires some organization, a lot of time and an animator. LittoSIM (Becu et al. 2017) is very realistic and aimed at emergency managers; SPRITE (Taillandier and Adam 2018) teaches risk management to engineering students; however, both games focus on longer-term management and protection against coastal submersion (e.g. building dykes) rather than communication.

\subsection{Role playing}

In serious games, the player can take their own normal role, an imaginary role (invented for the game), or another existing role. This change of perspective is a powerful tool to get people to understand the specific point of view and challenges of a different role, and can make it easier to accept decisions made by that role. (Shubik 1971) supports the usefulness of role playing a different position in order to understand another individual's point of view. Also of benefit in his view is the ability for participants to watch how stakeholders make their decisions in the game. This suggests that observing people playing can also be of interest, and that not only the players themselves learn from the game. This is also in line with Bowman's findings, that a "shift in perspective provides players with the opportunity to understand the motivations of others more clearly" (Bowman 2010), and that "the adoption of a role contributes to a greater awareness of one's own perspective, but also leads to an increased understanding of the perspectives of others" (Bowman 2014). 
Existing simulators are often aimed at training or supporting decisions of emergency managers. Here we adopt a different approach where we propose a serious game aimed at changing the population's perspective by letting them play the role of an emergency manager confronted with difficult decisions. Our game will provide the players with feedback about the reaction of the simulated population. In order to make this simulated population representative of reality, the underlying model is grounded on literature from psychology and sociology, as discussed in the next section.

\section{RELATED RESEARCH}

In order to simulate people accurately, it is essential to understand how they interpret crisis communications, what determines their trust, how they evaluate risks, and what motivates them to be vigilant and to take protective actions before a possible natural disaster. Below we define the concepts used in our study, and review related literature studying how people react to official crisis communication. This will provide the theoretical basis for modelling how the artificial population in Vigiflood reacts to the player's decisions in terms of communicating vigilance.

\subsection{Crisis communication}

(Samaddar et al. 2012) show the importance of integrated flood risk management, including both structural physical measures, and appropriate communication. Indeed, individual protective actions by the population could drastically reduce costs induced by flash floods (up to $80 \%$ according to (Grothmann and Reusswig 2006)). But crisis communication is complex, and emergency managers are trained about it (Reynolds 2010; Reynolds and Seeger 2014). It fills several functions. First, it informs people about risks, raising their risk awareness (Maidl and Buchecker 2015; Terpstra et al. 2009). It also keeps people vigilant despite repeated crises which could induce desensitization (Attansey 2012). Finally, it should motivate protective behaviours (Neuwirth et al. 2002).

\subsection{Subjective risk evaluation}

However, there is no similar training for citizens about receiving and interpreting crisis warnings. Studies show that people cannot predict the negative emotional impact of floods, which they greatly underestimate as long as they have not experienced floods (Siegrist and Gutscher 2008). They also have trouble interpreting probabilistic or statistical messages (Eiser 1998), they underestimate rare or extreme events (Burningham et al. 2008), and often rely on heuristics and cognitive biases (Murata et al. 2015; Arnaud et al. 2017).

Risk perception and evaluation is therefore highly subjective and emotional, depending on socio-cultural, environmental and linguistic factors (Infanti et al. 2013). Several authors study 
the role of culture (Douglas and Wildavsky 1983; Johnson and Covello 1987). Various cognitive and affective factors are also identified such as mental noise, stress, a focus on negative content, and lack of trust in the authorities (Covello and Sandman 2001; Covello 2003). For instance (Samaddar et al. 2012) study in Mumbai, India shows the importance of the population's trust in the information source on the resulting risk awareness and preparedness.

\subsection{Protection motivations}

But being aware of the risks is not sufficient to trigger protective actions (Grothmann and Reusswig 2006). For instance, an analysis of the behaviour of people during the Black Saturday bushfires in Victoria, Australia in 2009 (Fire Services Commissioner 2013) listed several profiles; this list includes a 'wait-and-see' behaviour where residents, although asked to leave early, would wait to see if the fire really came their way before evacuating, often too late, putting their lives at risk. A subsequent report focused on why people did not do what the authorities thought they should do (Rhodes 2014); they concluded that communication was not personalized enough, and did not target individual residents' motivations. (Boer et al. 2014) also find that communication should address the motivations of people to trigger preventive actions.

An important factor for motivation is the feeling of agency (Covello 2003) or locus of control (Hurnen and McClure 1997): if people believe they have no control (external locus of control) they will feel helpless, and be less likely to take preventative action or react to warnings. Similarly, (Khan et al. 2012) discuss the lack of response of the population when the perceived risk is either too high (fatalism) or too low ("blasé effect"): in both cases, people feel powerless.

(Floyd et al. 2000) review research about protection motivation theory (PMT), a model initially designed for disease prevention and health promotion. They find that both protective intentions and behaviours are facilitated by higher threat severity and vulnerability, higher selfefficacy, but also by decreasing rewards for maladaptive responses and costs for adaptive responses.

(Grothmann and Reusswig 2006) propose a psycho-social model of flood protection behaviours of residents of a flood-prone area in Germany, based on PMT, and evaluate it via a survey of residents of Cologne; they show that protective behaviours depend on factors such as previous flood experience, risk of future floods, efficacy and costs of self-protective behavior, but also on tendencies like wishful thinking; they conclude that in order to motivate residents, communication should not only be informative about risks, but also address the possibility, effectiveness and cost of protective measures.

(Siegrist and Gutscher 2008) compare people with and without flood experience, and find that if the latter are less motivated to take mitigation actions, it is because they strongly underestimate the negative emotional effects of floods; they conclude that flood communication should not only inform about technical aspects but also about potential emotional implications. 
Other authors identify affective factors playing a role in protection motivation. For instance (Harries 2008) show a tendency to refuse to take protection measures ensuring physical security, in order to preserve a feeling of security (or ontological security). (Weinstein et al. 2000) interviewed survivors of tornadoes to identify the effect of recollections of fear from previous disaster experience on intended protective actions.

\subsection{Trust}

According to Slovic (2016), risk management has become much more "contentious", with risk managers blaming the public for being irrational, and the public blaming the stakeholders for their poor management. In his view risk communication, aiming at aligning population and experts' perceptions with experts, has failed due to the lack of trust: "if trust is lacking, no form or process of communication will be satisfactory" (p. 410). Slovic also explains that trust is "fragile", builds up slowly but can be destroyed instantly and is then hard or impossible to regain (p. 319). He provides several reasons for this asymmetry. First, negative events are more visible than positive ones (one missed alarm stands out in many days of correct predictions). Second, negative events have more weight because they have lower probability and higher consequences (a flood is rarer than a "normal day" and it can do serious damage). Third, the media also tends to give more coverage to bad news than good news. Fourth, sources of bad news are seen as more credible, less likely to lie, than sources of good news. Finally, distrust strengthens itself, by limiting further interactions and biasing future interpretations towards the reinforcement of existing (distrustful) beliefs.

\subsection{Impact for Vigiflood}

Impact on our approach. Following this review of literature, our approach of proposing a serious game appears to be in line with the risk communication principles advocating transparency and empowerment of the population (Reynolds 2010), a field currently lacking research. The game format also favours engagement (Burke et al. 2009), which is important to maintain interest and vigilance over multiple crises (Attansey 2012), and repeated communication (Maidl and Buchecker 2015).

(Arvai 2003) concludes that public participation in decision-making about risks leads to higher quality decisions, with the resulting policies possibly being more acceptable. Our approach in this paper, consisting of surveying the population about the potential impact of such a game even before completely implementing it, is in line with participatory simulation (Becu 2020), which advocates to involve the stakeholders and final users right from the early stages of the design of the simulation. Our approach also facilitates a two-way dialogue with the population about flood risks; this is recommended by theory but not often enough observed in practice, according to a review of communication practices across Europe (Höppner et al. 2012) 
Impact on our model. To make our simulated population an accurate representation of reality, each artificial citizen (agent) will perform their own subjective risk evaluation, based on their personality and experience (Infanti et al. 2013), as well as cognitive biases such as the blasé effect leading to dismissing low risks (Khan et al. 2012); they will update trust based on received communications (Slovic 2016), building it slowly and losing it fast when perceiving 'mistakes'; and they will also make a personal protective decision (evacuate or not) based on this risk assessment, their emotions and trust (Grothmann and Reusswig 2006). The full details of our agent-based model are discussed in Section 5.

Impact for cultural portability. Risk evaluation depends on culture (Douglas and Wildavsky 1983; Johnson and Covello 1987), as well as on the type of disaster. For instance (Adam and Bailly 2019) report no habituation phenomenon to fire alerts in Australia, maybe due to a different risk culture, where people in scarcely populated, fire-prone areas, feel more responsible for their own safety, than residents of flood-prone areas in France. Besides, our case study is strongly context-dependent as well, supported by real rain data from the SouthWest of France, and using the French weather vigilance system (see details in Section 4). As a result, the Vigiflood tool will probably not be usable beyond France or Europe. Our target is therefore limited for the moment only to the French population of flood-prone areas.

\section{CONTEXT}

This section provides some context about flash floods and their impact, and the specific events in the South-West of France in October 2018 that constitute our case study.

\subsection{Flash floods}

Flash floods generally occur due to rapid rain on an already saturated soil (after a particularly wet period) or on a soil with a poor absorption capability (such as concrete, as is often the case in urbanized settings), or due to extensive rain because of a storm or hurricane. They can also occur from more occasional events such as a glacier melting after a volcanic eruption, an ice dam melting, or a man-made dam failing. They are quite hard to predict (Duan et al. 2014). In this paper we focus on rain-induced flash floods, whose prediction is the responsibility of the meteorological services. The indicators used by forecast services include: forecast quantity of rain (radar or satellite or model based), soil absorption capacity, soil moisture or dryness level, topography, basin or catchment capacity, etc. (CEPRI 2008).

\subsection{Facts and figures}

The Centre for Research on the Epidemiology of Disasters publishes an annual report based on the EM-DAT database (CRED Center for Research on the Epidemiology of Disasters n.d.). 
According to the its 2019 Review of Natural Disasters (Guha-Sapir 2019), in 2018, 315 natural disaster events were recorded, causing 11804 deaths, affecting over 68 million people, and costing 131.7 billion US\$ in economic losses across the world. This review also notes that floods are the disaster affecting the most people (50\% of the total), even though they are less deadly than earthquakes (respectively $24 \%$ and $45 \%$ of total deaths). Indeed, floods are the most frequent natural disaster, representing $40 \%$ of all natural disasters between the years 1985-2009 (Svetlana, Radovan, and Ján 2015), killing an average of 12700 people worldwide annually, and affecting 60 millions others; their economic impact is huge, whether in Asia (Duan et al. 2016) or in Europe, with the 2002 floods in Central Europe costing about 20 billion US\$ (Svetlana et al. 2015).

The European Commission (2019) reports 213 recorded flood events between 1998-2009, causing 1126 fatalities, and costing about 52 billion $€$, making it the costliest type of disaster (followed by storms). There are also enormous stakes, with over 10 million people living in extreme-flood-prone areas along the Rhine river alone, and potential damage estimated at 165 billion $€$. Coastal areas are even more exposed, with economic assets located within 500 meters of the European coastline valued between 500 and 1000 billion $€$. (Paprotny et al. 2018) analyzed the HANZE database floods records in Europe between 1870-2016: they found 1564 records of floods, $56 \%$ of the total being flash floods (river floods under 24 hours); in southern Europe flash floods are even more prevalent, mostly between September and November. This is precisely the context of our case study: an extreme flash flood occurred in the South West of France in October 2018.

\subsection{French flood vigilance system}

French vigilance system. The current French vigilance system was designed in 2000 after the 1999 storms, and implemented in 2001 for a first set of meteorological events, then completed with heat waves in 2004, and combined rain-flood vigilance in 2007 (Degrace and Honore 2010). It is a meteorological watch and warning procedure where Meteo France, the national weather forecast agency, provides expertise to the prefects, the Civil Defence Organisation, the relevant stakeholders, and the general public. It is improved over time after feedback from events (Daupras et al. 2015).

According to Meteo France, ${ }^{2}$ the agency in charge of rain forecasts, weak rain is defined as 1 to $3 \mathrm{~mm} / \mathrm{h}$, moderate rain is between 4 and $7 \mathrm{~mm} / \mathrm{h}$, and heavy rain is over $8 \mathrm{~mm} / \mathrm{h}$. Another agency is in charge of monitoring the main waterways and broadcast their expected height and debit 3 to 6 hours ahead of time: Vigicrues ${ }^{3}$. However, only part of the waterways is monitored, and the European Flood Risk Prevision Center (CEPRI ${ }^{4}$ notices that half of the 63 victims in

\footnotetext{
${ }^{2} \mathrm{http}: / /$ www.meteofrance.com/previsions-meteo-france/previsions-pluie

${ }^{3}$ www.vigicrues.gouv.fr

${ }^{4}$ https://www.cepri.net/
} 
the Languedoc-Roussillon region (south of France) alone between 1996 and 2006 died on catchment basins that were not monitored.

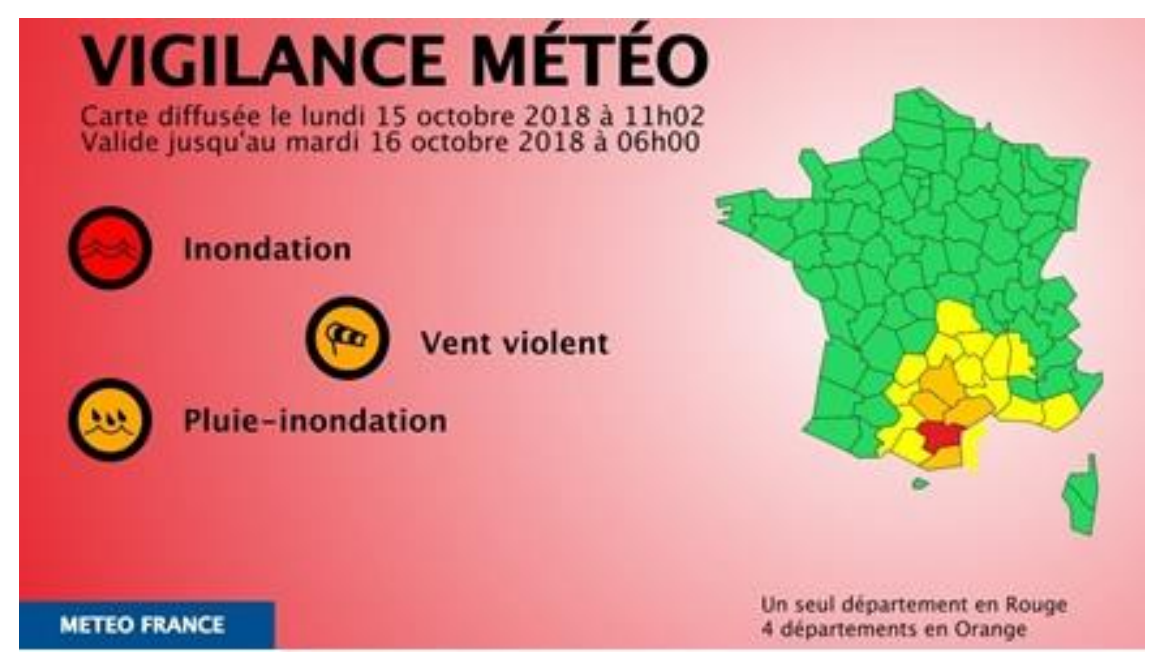

Figure 1. Meteo France vigilance map, 15 October, 11 am (source: Meteo France)

Vigilance scale. The meteorological services in charge of the area then analyses these clues (rain forecast, waterway height and debit, etc.) to define and announce a level of vigilance on a 4-colour scale, from green (no problem), yellow, orange, to red (higher risk). Table 1 gives the official ${ }^{5}$ definition of each level. This level of vigilance is publicly available online ${ }^{6}$ (example map on Figure 1). Each region has its particularities and can be more or less used to receiving heavy rain in a short amount of time, so that the vigilance thresholds are not the same everywhere.

Over-alerting (false alerts) vs under-alerting. But such extreme phenomena are hard to predict, and weather forecasting agencies are faced with a dilemma: alerting while uncertain about the occurrence of an event, with the risk of 'over-alerting' (or 'false alarm' as can be reported in the media (Le Monde 2018), meaning that the event forecasted does not happen; or waiting to have better certainty before alerting, with the risk of 'under-alerting', i.e. failing to alert before an actual event. Over-alerting is considered less risky in terms of immediate lives lost, and Météo France allows about $15 \%$ of over-alerts, while missed alerts can have very serious consequences, and only 2-3\% of yearly events are missed (statistics provided by Météo France in an interview in the news after the 2018 floods (Le Monde 2018)). However, overalerting can also be risky over the longer term by destroying the population's trust, as shown by the following case study.

\footnotetext{
${ }^{5}$ Translated from French from: https://vigilance.meteofrance.com/html/vigilance/guideVigilance/vigilance.html

${ }^{6}$ See: http://vigilance-public.meteo.fr/or: http://vigilance.meteofrance.com/
} 
Table 1. Official definitions of flood vigilance levels (translated from Météo France)

\begin{tabular}{|l|l|}
\hline Color & Definition \\
\hline Green & No specific vigilance needed \\
\hline Orange & $\begin{array}{l}\text { Be careful; if you engage in activities that are sensitive to the weather or near a } \\
\text { shore or stream; common phenomena in the region but occasionally and locally } \\
\text { dangerous are indeed predicted; keep abreast of developments. }\end{array}$ \\
\hline Red & $\begin{array}{l}\text { Absolute vigilance is required; dangerous phenomena of exceptional intensity } \\
\text { are pre-dicted; keep abreast of developments and be sure to follow the safety } \\
\text { instructions issued by the government. }\end{array}$ \\
\hline
\end{tabular}

\subsection{Case study: Aude floods, October 2018}

The Aude department in France (see map on Figure 2) depends on the CNP center in Toulouse; its critical rain threshold for the orange vigilance is $50-100 \mathrm{~mm}$ in 24 hours, with a regional record of $551 \mathrm{~mm}$ in 24 hours. On Sunday 14 October 2018 the meteorological station of Carcassonne received $139.8 \mathrm{~mm}$ of rain. The vigilance level was initially set to orange due to high uncertainty, then raised to red Monday 15 October morning at 6am. In the meantime, several towns were already flooded, roads and bridges destroyed, and some people had died. The final toll of these floods in the Aude department is 15 dead and 99 injured people, 204 towns classified as hit by "natural disaster", and a total cost of damages estimated to $220 \mathrm{M€}$.

As a result, Météo France vigilance system was harshly criticized in the media (Libération-AFP 2018).

The representative of the French Ministry of the Interior, Frédéric de Lanouvelle, interviewed on LCI-TV, evoked a "weakness in the orange vigilance level which is used very often and when there is a real problem, people do not take it into account anymore" (our translation). He adds that based on residents' statements, the red vigilance level was indeed raised too late, but he explains that it is due to the difficulty in forecasting such a powerful episode. However, as noted by the Major Risks Institute (IRMA) (Gominet 2018), there had only been 3 orange vigilances raised in 2018 in the Aude department for rain-floods before October 14: January 7-8; 28 February and 1st of March; and the last one on October 9-10, immediately following an orange vigilance for thunderstorms on October 8-9. Besides, this last episode probably influenced the dramatic floods of October 14-15 by saturating the soil with water. (Gominet 2018) therefore concludes that the general public must be made aware of their responsibilities, and be taught that several orange vigilance events in a row should make them 
particularly vigilant, instead of the opposite, dismissing the last vigilance because nothing serious happened during the previous ones.

Our approach precisely intends to favour this empowerment of the population, raising awareness and instilling responsibility, by letting them take on the role of a weather forecaster in order to understand the difficulties faced. The next section describes our serious game and underlying model.

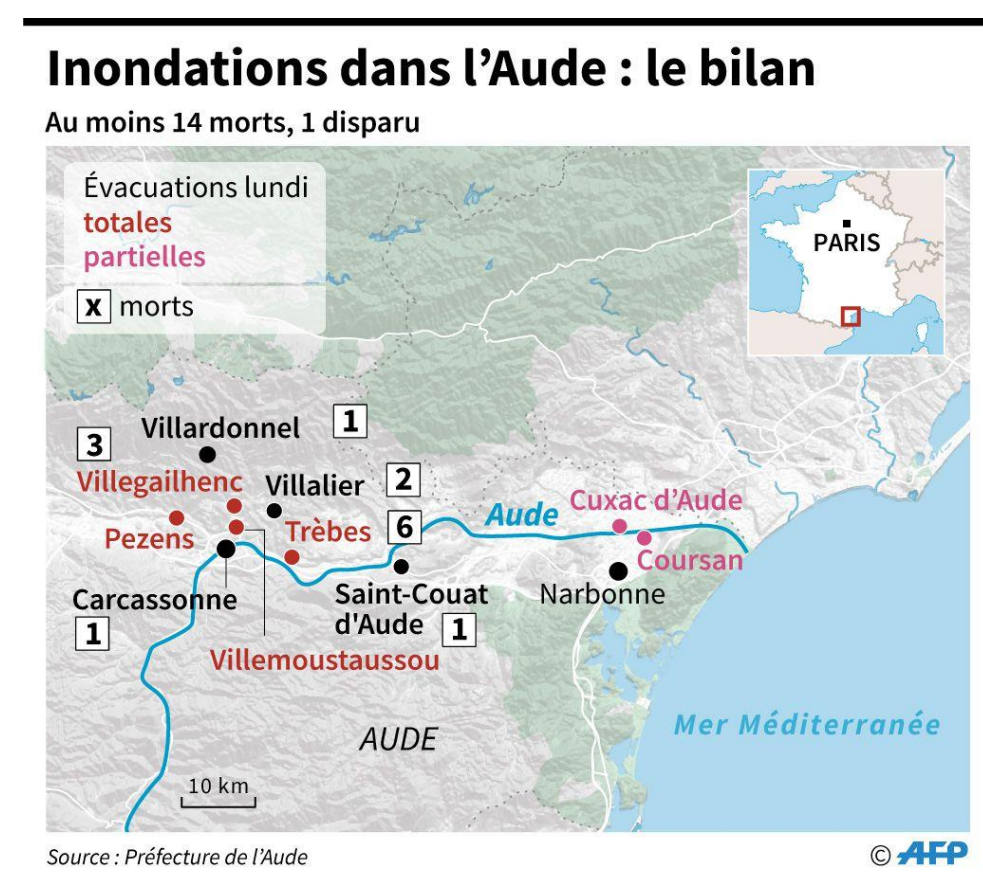

Figure 2. Map of the flooded area, with victim counts and evacuated towns.

Source: Préfecture de l'Aude.

\section{VigiFlood}

The VigiFlood serious game is implemented in Python (Adam and Andonoff 2019). It is based on actual rain and vigilance data, and on a conceptual agent-based model of human behaviour in flash floods grounded on the literature described in Section 3 above. This section provides a quick overview of the interface of the game, the scenario and data, and the underlying conceptual model, before we proceed to describing its evaluation.

\subsection{Game interface and gameplay}

The idea of Vigiflood is that the player takes the role of risk communicator, having to decide the vigilance level (color between green, yellow, orange, red), based on uncertain clues (rain forecast). Their actions influence the population, whose trust and subjective risk level evolve over time, and who might or might not evacuate when floods are announced; they can also 
trigger various events simulating the reactions of institutional actors to the vigilance level (closing schools, stopping school bus services, closing roads, etc.) and the impact of rain or floods on the environment (collapsed bridge, etc.). The player can observe the impact of their actions through various information panels. The following paragraphs detail the narrative and interface of the game.

\subsubsection{Game narrative}

The game loop proceeds in the following phases:

1. The date of the day is displayed, as well as the observed amount of rain that day (in $\mathrm{mm})$.

2. The residents react to the observation of the rain: they compare it with the current vigilance level (set the day before) to update trust, and they might evacuate if needed.

3. The player is provided with feedback about the population: average trust and its explanation (in terms of how much rain they expected based on the vigilance colour); and percentage of evacuated residents.

4. The weather forecast service announces a forecast amount of rain for the next day.

5. The player is asked to set a vigilance colour based on this forecast.

6. The population reacts to this vigilance level: compute subjective expected rain based on previous similar alerts, and might evacuate if this is above their risk aversion threshold;

7. The player receives feedback about the population's risk awareness percentage; their average expected rain (in $\mathrm{mm}$ ); their average trust (in \%); and the percentage that evacuated as a result of the alert.

8. Daily rain and vigilance are stored in game history, time moves forward to the next day.

\subsubsection{Interface}

The interface (shown on Figure 3) comprises several parts. The weather tab (white, left side panel) reminds the date, the observed rain, the forecast for the next day (mm of rain), and the last announced vigilance colour. The population tab (light blue, center panel) details the average subjective risk (expected rain) in the population for each vigilance colour, the average trust in vigilance messages (with its last evolution due to the last message sent by the player), the percentage of population that is unaware of risk (i.e. their subjective risk evaluation is lower than the objective risk), and the evacuation percentage. The communication tab (green, right panel) provides communication statistics, namely the number of days played, and for each colour of vigilance, the number of vigilances raised, the number of over-alerts (raised, but observed rain was lower than expected/announced), and the number of under-alerts (missed, i.e. not raised but the observed rain was higher than expected/announced). Four vigilance 
buttons at the bottom of the window allow the player to select the desired vigilance colour (green, yellow, orange, or red). Finally, popups can appear on top of the main window to display various events triggered by the player's actions.

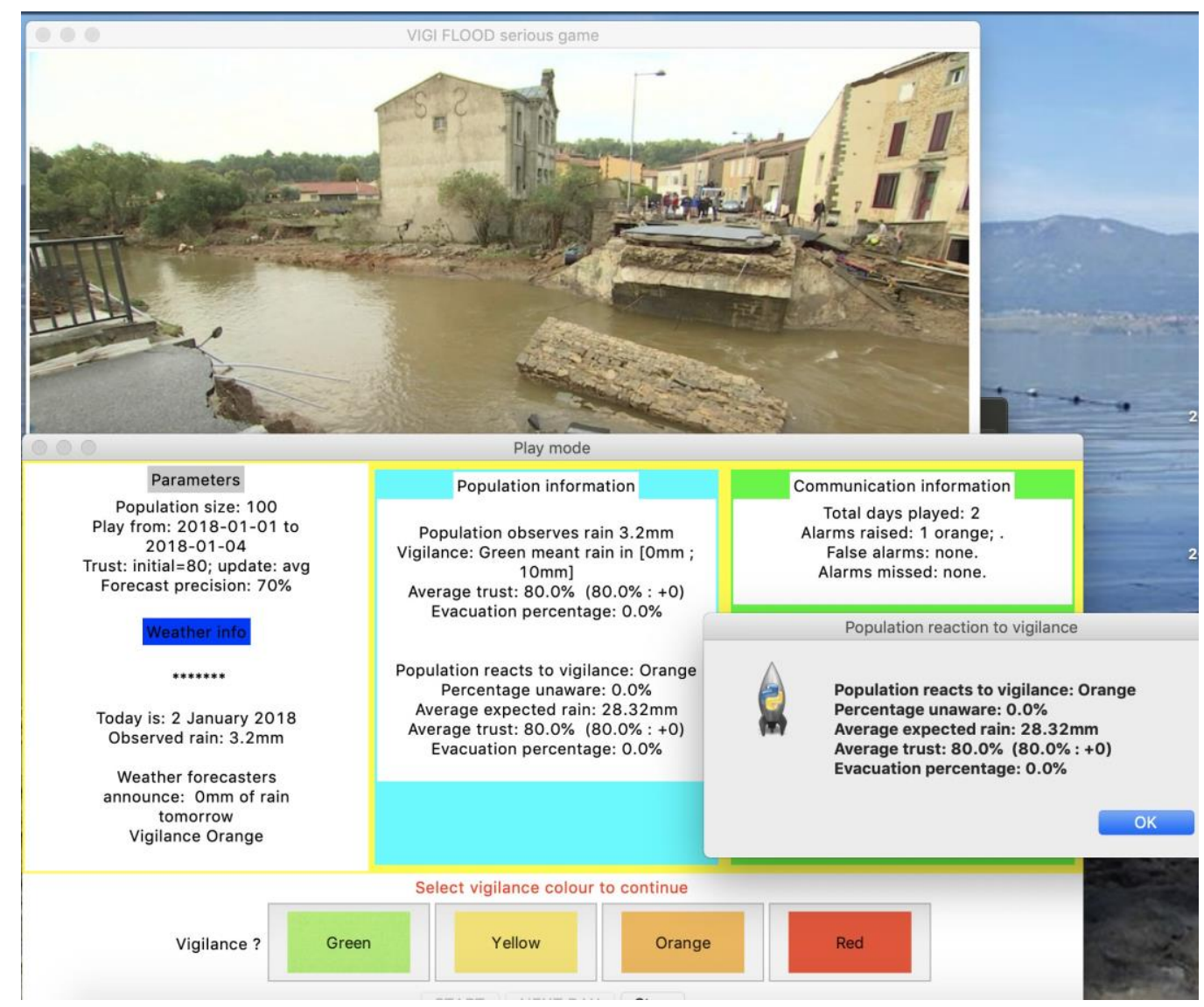

Figure 3. Screenshot of the game interface

\subsection{Scenarios and data}

The game can be played either with a realistic scenario using actual rain and vigilance data, or with a generated pedagogical scenario that places them in specific intended situations aimed at testing their reactions. The advantage of the generated scenario is to accelerate the game and control the desired pedagogical sequence. Real data was extracted with Python scripts, from public meteorological archive websites.

Rain data was extracted from Infoclimat ${ }^{7}$, which provides archives of daily, monthly and yearly meteorological data (temperatures, wind, rain, etc.) since 1973 . We focused on Carcassonne-Salvaza, a meteorological station of the town of Carcassonne, the prefecture of the Aude department that was the most impacted by October 2018 floods. We extracted the following data for the years 2010-2018: normal monthly rain (seasonal norms computed by

\footnotetext{
${ }^{7}$ Infoclimat: https://www.infoclimat.fr
} 
Infoclimat between 1981-2010), number of days of rain (at least $1 \mathrm{~mm}$ ) per month, and actual daily readings of rain amounts.

Vigilance data was extracted from Vigilance Public Meteo $^{8}$ which provides maps and details of daily departmental vigilance alerts: time, level (green, yellow, orange, red), emitting agency (each covering a different region; Aude department depends on the CNP agency in Toulouse), and phenomenon concerned (floods, high winds, waves and coastal submersion, snow and black ice, etc.). We extracted the daily rain and floods vigilance colours for the Aude department between 2010 and 2018 (green if no bulletin; higher colour if multiple ones).

\subsection{Underlying conceptual agent model}

Our approach is to use an agent-based model of the population and their reaction to their environment (vigilance level, observed meteorological events). The validity of this behaviour model is ensured by its grounding on psychological and sociological theories of trust and risk communication described in Section 3. The physical model of flood on the other hand need not be extremely realistic to reach an educational goal, in line with (Axelrod 1997). This conceptual model has already been described in (Adam and Andonoff 2019). This section reminds the characteristics of the agents representing the residents: their attributes, how they subjectively evaluate risk, how they update their trust, and how this subsequently impacts their behaviour.

\subsubsection{Attributes}

The population is composed of a number of heterogeneous resident agents, that have the same attributes (summarized in Table 2) but differ by their values.

\subsubsection{Subjective risk evaluation}

Residents receive vigilance alerts, which indicate an 'official' level of risk, but not all residents equally believe in this level of risk. Indeed, each resident first subjectively evaluates risk (i.e. expected rain) based on their memory depth and on their risk evaluation strategy which reflects their personality. Optimistic residents consider the minimum amount of rain observed during past events where the same vigilance colour was raised; if a false alarm was raised in the past this can lead theú to expect no or very little rain. Pessimistic residents consider the maximum amount of rain; this is very forgiving to false alarms. Rational residents consider an average of observed rain on remembered past occurrences of the same vigilance level. Finally, short-memory residents consider only the last occurrence of the same vigilance level; this simulates the loss of risk memory observed over time when no significant disaster happens (Fanta et al. 2019).

\footnotetext{
${ }^{8} \mathrm{http} / / /$ vigilance-public.meteo.fr/
} 
Table 2. Attributes of agents in the simulated population

\begin{tabular}{|l|l|l|}
\hline Attribute & Value & Details \\
\hline Subjective risk & Float, 0 to 1 & $\begin{array}{l}\text { Can be over-estimated or under-estimated compared } \\
\text { to -inaccessible- objective risk) }\end{array}$ \\
\hline $\begin{array}{l}\text { Risk aversion } \\
\text { threshold }\end{array}$ & Float, 0 to 1 & $\begin{array}{l}\text { What level of risk they can tolerate before they } \\
\text { choose to evacuate }\end{array}$ \\
\hline $\begin{array}{l}\text { Trust in vigilance } \\
\text { messages }\end{array}$ & Float, 0 to 1 & $\begin{array}{l}\text { How much they believe the level of risk } \\
\text { announced by the authorities }\end{array}$ \\
\hline $\begin{array}{l}\text { Memory } \\
\text { depth/experience }\end{array}$ & Integer & $\begin{array}{l}\text { How many past flood or vigilance events } \\
\text { they remember }\end{array}$ \\
\hline $\begin{array}{l}\text { Risk evaluation } \\
\text { strategy }\end{array}$ & $\begin{array}{l}\text { Optimistic, } \\
\text { pessimistic, } \\
\text { rational, short- } \\
\text { memory }\end{array}$ & $\begin{array}{l}\text { How they evaluate risk based on these events, in } \\
\text { line with psychological theories saying that } \\
\text { humans evaluate risk based on previous experience } \\
\text { and emotions (Reynolds and Seeger 2014) }\end{array}$ \\
\hline
\end{tabular}

\subsubsection{Interleaving with trust}

Trust and risk are interleaved in the individual assessment process. On the one hand, trust mediates subjective risk assessment: each resident ponders their personal risk assessment vs the official communicated risk based on their (dynamic) level of trust in the vigilance alerts. Concretely, if trust is $100 \%$, the resident will fully trust the official risk and expect exactly the amount of rain corresponding to the vigilance colour; if it is $0 \%$, they will fully trust their own judgement and expect exactly the subjective value resulting from their past experience. On the other hand, residents then observe real rain and compare it with their expectations. If they are surprised by the actual amount of rain (either because it is higher or lower than expected / announced), their trust in the forecast will decrease (more if a flood was un-announced than in case of false alarm; and more for higher impact events). On the contrary if the observation is in line with expectations, trust will only slightly increase, as this is judged as being normal.

\subsubsection{Biased decision making}

Finally, the residents' decision to evacuate early is based on the comparison of their subjective risk value with their personal risk aversion threshold. They can also evacuate after directly observing high amounts of rain (exceeding their aversion threshold), but this often happens too late, hence the importance of maintaining trust in pre-flood warnings. Loss of trust pushes residents to neglect the official communicated risk, which can lead to two opposite situations. After over-alerting (false alerts), personal risk assessment is low (memory is full of events with high vigilance but low rain); neglecting official risk conduces to underestimating risk. Potential consequences can be serious, such as a failure to prepare and evacuate 
in time. On the contrary, after under-alerting (missed alerts), personal subjective risk assessment is high (memory contains events with low vigilance but high rain); neglecting official risk conduces to over-estimating risk. Potential consequences include over-reacting or panic (P. Sandman 2003); it can also lead stakeholders to take unnecessary measures.

\section{EXPERIMENTAL EVALUATION}

The game described above is designed to induce a change of perspective, where normal residents are put in a decider's shoes and faced with the responsibility to set the vigilance level themselves. We now want to check if such a change of perspective does actually improve users' awareness of the difficulty to set vigilance without mistakes, and of their own responsibility for being vigilant; and if it does trigger a shift of behavioural intentions towards more protective actions. In order to test the impact of our game, we have designed a questionnaire simulating the role-playing experience, and administered it online in order to reach a wide audience.

The following paragraphs describe the questionnaire, the recruitment of participants, and the results along 2 axes: the (objective) impact that the game had on awareness and protective intentions; and how the participants (subjectively) judged the game.

\subsection{Questionnaire}

The questionnaire is written in French. The complete list of questions, translated into English, is available in Annex 1. It was proof-read by a linguist, and validated by an ethics and data privacy consultant. It has also received the agreement of University Grenoble Alpes ethics committee $^{97}$. It is designed to proceed in the following six phases:

1. Assess the responders' previous experience, knowledge of and trust in the French vigilance system.

2. Assess the responders' awareness of risk, challenges, own responsibility; and behavioural intentions in case of floods (before playing).

3. Change of perspective: role-playing exercise of setting the vigilance level, in different more or less complex situations, with different clues.

4. Subjective evaluation of the game by responders: interest, usefulness, willingness to use it.

5. Re-assess the responders' awareness of risk, challenges, own responsibilities, and their behavioural intentions in case of floods (after playing).

6. Demographic questions to categorize responders.

\footnotetext{
${ }^{9}$ Agreement number CER Grenoble Alpes-Avis-2019-09-24-5
} 
The comparison of scores between phase 2 and phase 5 will allow us to measure the impact of the role-playing experience (phase 3 ) on the indicators measured. The scores in phase 4 allow to gather the respondents' opinions about such a game, in line with a participatory approach. Answers to phase 1 and phase 6 will let us categorize responders in terms of their experience and demographic characteristics, to ensure representativity and to compare impact on different categories.

\subsection{Recruitment of participants}

We recruited adult participants by broadcasting the link to the questionnaire via email, through the author' professional and familial networks. The goal was to reach a wide audience, avoiding a classical bias of only testing software with computer scientists and students, and get answers from people with and without flood experience to enable comparisons.

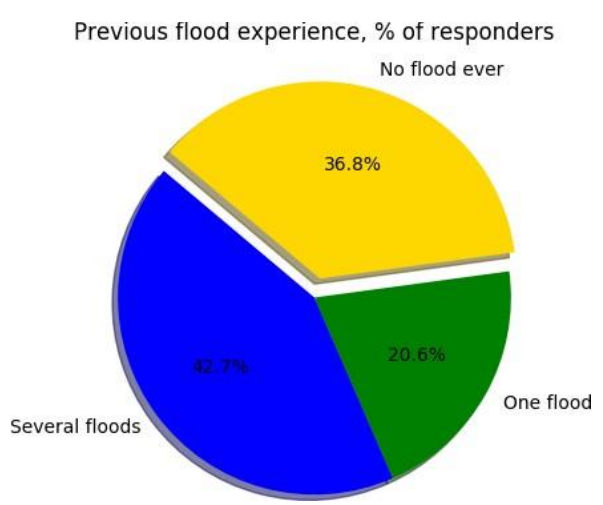

Figure 4. Experience

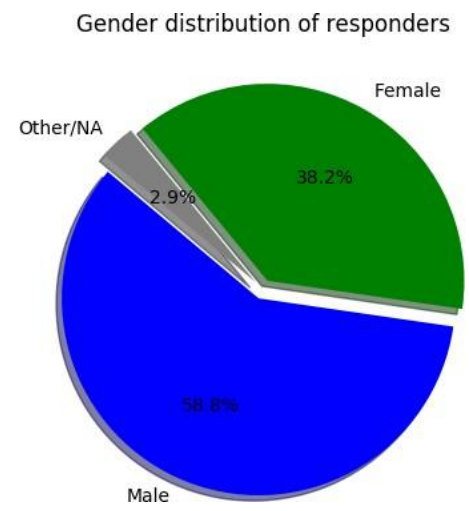

Figure 6. Gender

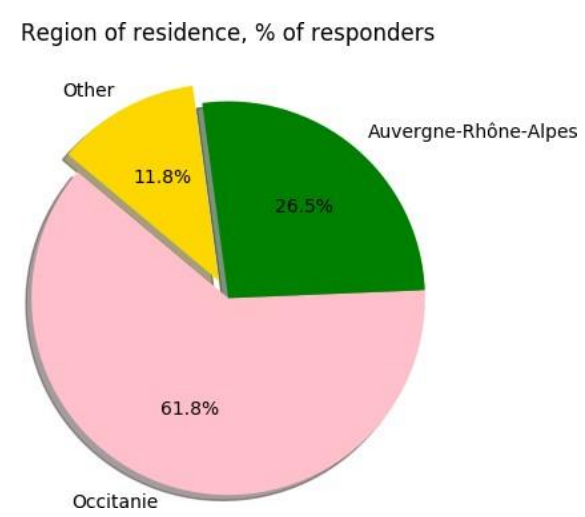

Figure 5. Residence

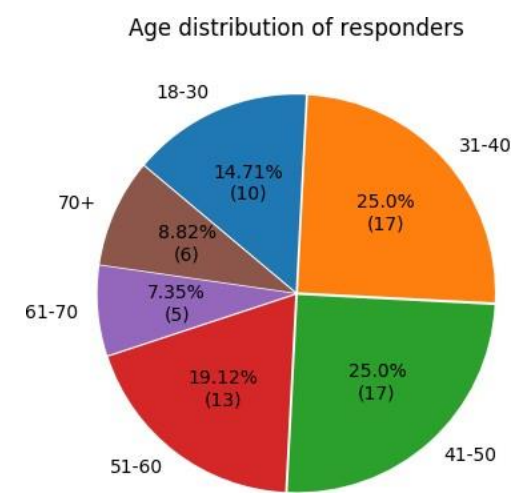

Figure 7. Age

The online questionnaire has received 80 answers. The pie charts in Figures 4 to 7 show that our sample was rather representative with responders from all age groups, slightly more males than females, and having different levels of experience with floods. Due to our mode of recruitment, the responders mainly live in 2 regions: Occitanie (South-West region of France 
where the October 2018 floods occurred, reached via familial network) and Auvergne-RhôneAlpes (South-East region of France where the author works, reached via professional network).

\subsection{Results: objective impact of the game}

The main goal of this questionnaire was to assess how role-playing and changing perspective (through a simulation of the Vigiflood game) can impact the players' attitudes. We measured a number of criteria defined in Section 3: awareness of risks (is the person aware of the risk of floods in the area) and of own responsibility (does the person feel responsible for their own safety in case of floods); impact of events interpreted as 'false alarms' on trust (does the person lose trust when an orange vigilance is not followed by a significant flood?) and on vigilance (is the person more or less vigilant after repeated 'false alarms'); and intended protective actions in case of orange or red vigilance (what does the person intend to do in case of high vigilance). We measured these criteria both before (phase 2) and after (phase 5) the change of perspective induced by the core of the questionnaire (phase 3).

\subsubsection{Impact on awareness}

Figure 8 shows how awareness scores evolved between before and after the role-playing sequence. We can see that risk awareness increases for orange vigilance events (that tend to be ignored when too frequent), which is a good thing. It does not increase for red vigilance events, which are already alarming enough.

The awareness of own responsibility in self-protection does not change significantly after the game, probably because the focus was more on the alert phase, and the game does not show actions of the population; further developments of the software will try to focus more on the population side.

Finally, awareness of the difficulty of setting the right level of vigilance does increase, less people feel that a forecast should only be announced when it is certain, and the minimal reliability for announcing a vigilance also decreases. This is in line with serious game research showing that a change of perspective does induce a better understanding of the other role: after being faced themselves with the dilemma of potentially under- or over-alerting the population, the players seem to reduce their expectations. We hope this should limit the subsequent loss of trust induced when the vigilance colour is perceived as wrong: errors are easier to forgive when the difficulty of the task is known. 


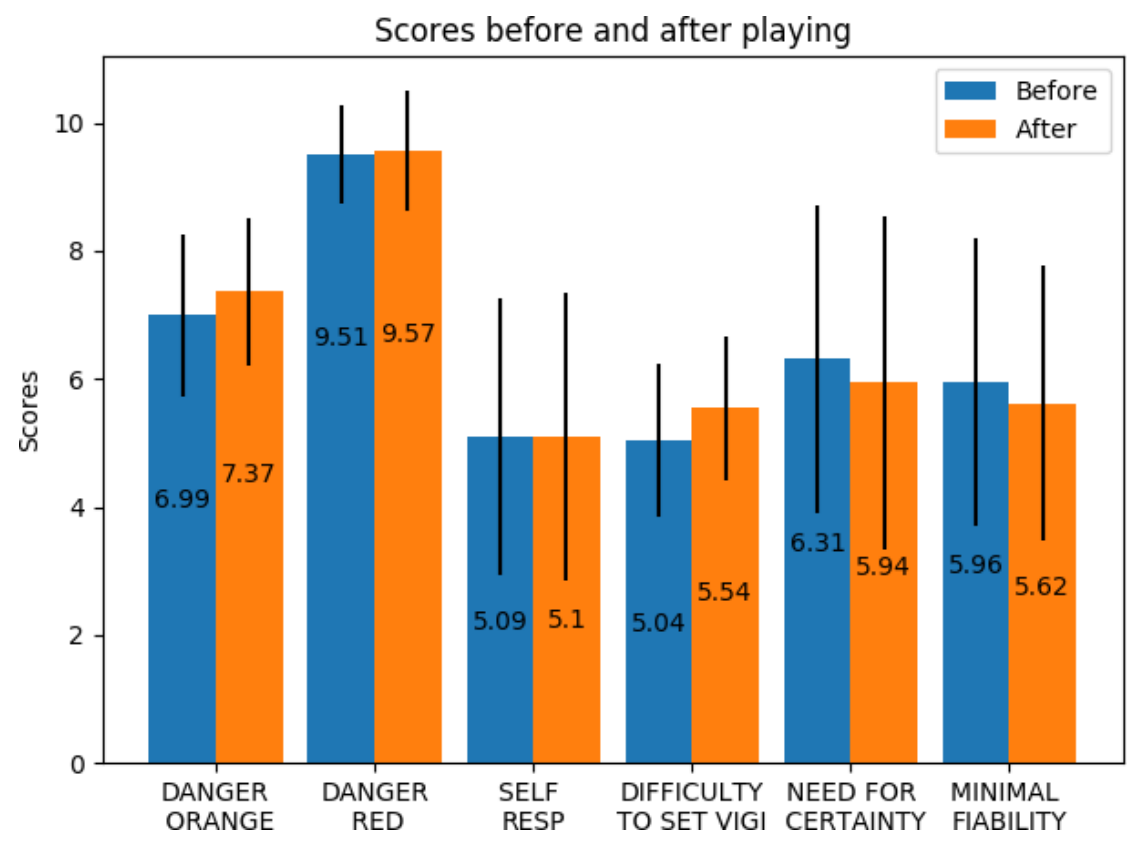

Figure 8. Evolution of awareness scores before/after playing

\subsubsection{Impact of 'false alerts' on vigilance}

As suggested by (Attansey 2012), vigilance can fade after several occurrences of a same disaster. This is confirmed by our survey. Figure 9 illustrates the dynamics of population vigilance over multiple alerts. It shows that before playing (blue bars) $17.65 \%$ of responders report being less vigilant after what they perceive as a "false alert", while $14.71 \%$ report never being vigilant anyway. This is worrying for several reasons. First, "false alarms" can be quite frequent, because it is hard to predict such phenomena, and because the vigilance is set at the entire department level. Therefore, even if a flood does indeed happen locally, it is possible that a large part of the department is spared and left to believe that it was a false alarm. Second, even if it is actually a false alarm and no flood happens this time, intense rain might leave the soils saturated and river levels very high, thus favouring future floods if more rain happens later. As a result, past alerts should increase vigilance rather than decreasing it.

Our main idea was to reduce this loss of vigilance by explaining that vigilance announcements are necessarily probabilistic, and that some errors are unavoidable. Figure 9 indeed shows that after playing (orange bar) there is a significant increase of people stating that they will be "always vigilant" when under orange vigilance even after several 'false alerts' (rising from $58.82 \%$ to $67.65 \%$ ). In contrast, there are less people stating they would be "less vigilant", "more vigilant", or "never vigilant" after "false alerts". This is an important impact of our role-playing experiment, since we have seen that the key issue during the October 2018 floods in Aude was this habituation and loss of vigilance (Le Monde 2018). 


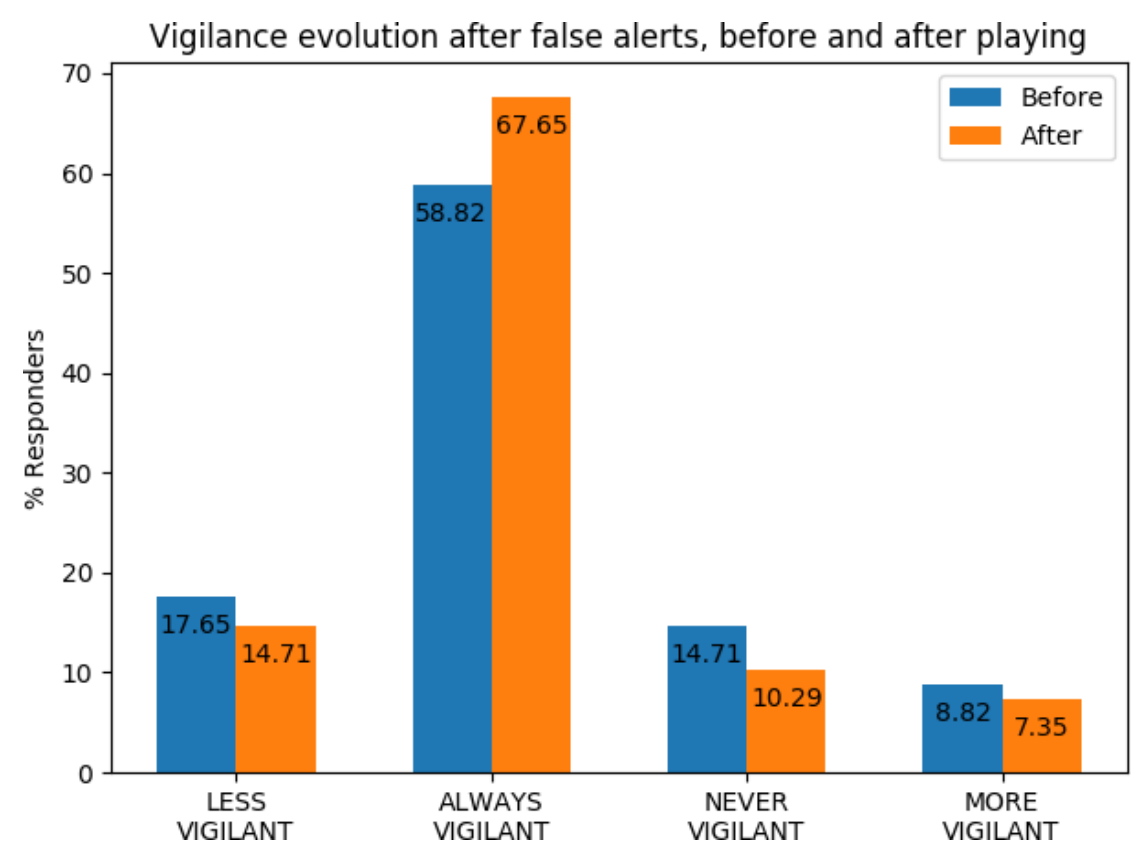

Figure 9. Evolution of loss of vigilance with false alerts, before/after playing

The survey was administered to many people having recently lived the October 2018 floods, which explains why most users in our sample are already very vigilant. Further analysis is required to compared the dynamics of vigilance in responders with or without flood experience. It would also be interesting to compare with people having a less recent flood experience, as the literature reports how humans tend to cyclically forget about risk until a new crisis occurs.

\subsubsection{Protective measures taken}

Figure 10 illustrates the percentage of responders taking various protective measures, before (questions in phase 2 of the questionnaire) vs after playing (same questions in phase 5 of the questionnaire). The actions mentioned in the survey are: search information (INFORM); share information (SHARE); prepare house; gather with relatives and family (GATHER); park one's car on higher ground (PROTECT CAR); evacuate; or do nothing special. In the figure, each bar shows in orange the percentage of responders saying they would take this action when an orange vigilance is announced, and in red at the top the additional percentage of responders saying they would take this action only when a red vigilance is announced. The left part (uniform colour) of each bar is before the game, while the right part (starred colour) is after.

The left bar measures the percentage of responders doing "something" at all. We can see that about a quarter of the population would do nothing at all in case of orange vigilance $(24 \%$ before the game, $22 \%$ after); very few would do nothing if there was a red vigilance ( $8 \%$ before the game, $6 \%$ after). This high level of behavioural intentions is probably due to our sample comprising more people with flood experience (and therefore more prone to take protective actions) than the general population. 
The most frequently intended action is to search for information: $78 \%$ will try to get more information in case of an orange vigilance, and an additional $10 \%$ (so a total of $88 \%$ ) in case of a red vigilance. These percentages rise to $82 \%$ and $91 \%$ after playing the game. We see a similar impact on the actions of sharing information, gathering with family, or evacuating (which is mostly envisaged in case of red vigilance). On the other hand, intentions for preparation actions (preparing house and protecting car) decrease slightly in case of orange vigilance, but increase in case of red vigilance.

This hence shows that changing perspective through the questionnaire has modified the protective intentions of the responders. These are only declared intentions and might be influenced by a willingness to give the "right" or expected answer. But in that case, it shows an improvement after the game of the awareness of actions that should or should not be performed. Declared intentions might also be actual intentions but not lead to actions once under stress in a real flood situation. It is nevertheless encouraging, and such communication should be repeated to further motivate protective behaviours.

\subsection{Results: subjective evaluation of the game}

The objective evaluation above is encouraging, but to have an impact, such a role-playing experience needs to be actually played by people in flood-prone areas, possibly in a repeated manner. This will require it to be interesting, engaging, motivating. We therefore asked the responders to score VigiFlood (in its simulated version administered via the online questionnaire) on 5 criteria: how interesting was it to answer or play; how boring is the current gameplay; how useful is Vigiflood to learn about floods, forecast and communication; are they willing to see such a game offered as training by the town council; are they willing to see such a game integrated in school programs about natural hazards.

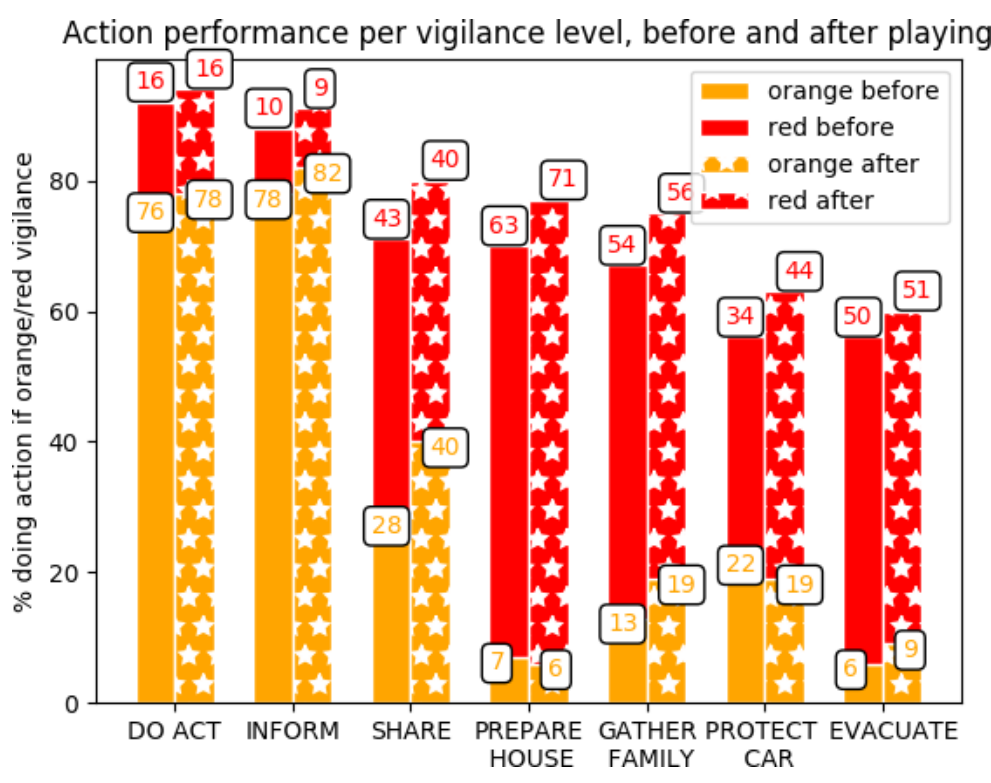

Figure 10. Evolution of actions performed/intended if orange/red vigilance, before/after playing 
Figure 11 summarizes the results in the form of a boxplot diagram: the boxes extend from lower to upper quartile values of the scores, with a line at the median; the whiskers extend from the boxes to show the range of the data; outliers are not shown here.

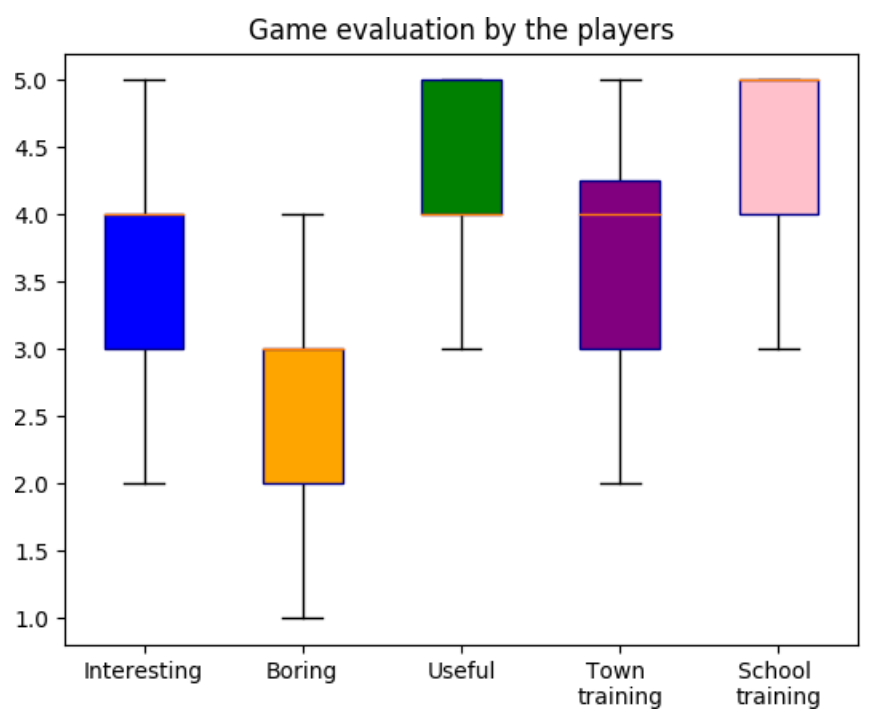

Figure 11: Evaluation of the game (5-point scale scores): interest, boredom, usefulness, willingness to use it for training of town residents (by town council), or for training of school children (by professors).

We can see that responders find the game very useful (avg=4.18; stdev=0.98). They are willing to have it offered by their town council as training (avg=3.79; stdev=1.08), and even more willing to see it offered to children as part of school programs about natural hazards (avg=4.35; stdev=0.84). However, even though they found the concept of the game quite interesting (avg=3.65; stdev=1.04), they also judge the gameplay rather boring (avg=2.51; stdev=0.95). Future work is therefore needed to improve immersion and engagement with the game; this is the current direction of the project. We will also further analyze if these scores are different between people with or without flood experience.

\subsection{Conclusion of the evaluation and future work}

This survey was intended to show the potential of such a serious game for getting the population of flood-prone areas to change perspective. Since the software is still under development, and to allow for a wider participation in different regions, it was decided to run the survey online via a questionnaire that simulates the intended functioning of the Vigiflood game. This is a first limitation, since we evaluated a slightly different process than that of the actual game. However, we believe that both versions do induce the same change of perspective, which is the key element of our approach. 
Besides, we believe it is important to get feedback from target users very early in the development process, in line with a participatory research approach. As such, the subjective evaluation is very important to validate the idea of this game before putting efforts into implementing it completely. The results are encouraging, proving that such a serious game would be welcomed by the population of flood prone areas. They will also orient further developments towards improving the gameplay and immersion in the game.

The survey measured the impact of this role-playing exercise on the users' awareness, vigilance, and protective actions intentions. Our results show a positive impact on these indicators, which is encouraging. Another limitation of this survey comes from our sample of responders. The survey was broadcast through personal networks in the affected areas. Besides, only people who felt concerned with floods and motivated by the topic would take the time to answer the survey, given its repetitiveness and lack of engaging features. We hope that the final software, once we make it less boring and more immersive, will do even better in allowing the users to change perspective and to gain insight about flood risk communication. The gameplay design and implementation is the subject of ongoing work; we then aim to use this serious game with high school students and evaluate its impact.

Further analysis will also be performed on the answers, to categorize the users' risk evaluation strategies (what strategy do they use to choose a vigilance level), or to compare answers of different profiles of responders (with or without flood experience; by age or gender; etc.). This should lead to a better understanding of the population's subjective risk analysis and the factors influencing it. Such insight will be important to inform communication strategies of emergency managers. We are working with Météo France towards this goal.

This is in line with (Yamori 2012) who found that participative approaches promoted the population's engagement and responsibility, compared to vertical knowledge-passing approaches. The difference is that they designed a card game while we implemented a computer game; further research would be needed to compare engagement of the different formats, maybe depending on the target users. Our target being students, the engaging potential of digital games has already been proven (Bottino, Ott, and Tavella 2014).

\section{CONCLUSION AND PROSPECTS}

In this paper we presented Vigiflood, a serious game for raising awareness about the challenges of flood risk communication. In relies on an agent-based model of the population's trust and decisions, itself grounded in psychology and sociology of human behaviour. A first prototype of the game is implemented and functional. It lets the player choose the flood vigilance colour (green, yellow, orange, red) based on the weather forecast (generated from real meteorological data extracted from archives for the target area). It is therefore a roleplaying game where the users (residents in flood prone areas) take on a different role in the game (that of weather forecasters) than in real life. The main idea behind this game design is that the change of perspective induced by playing a different role will lead to a better 
understanding of the difficulties of this role, specifically here the challenges of announcing the "right" level of vigilance.

The main contribution of this paper is the evaluation of the concept of the game. We ran an online survey replicating the role-playing part of the game, preceded and followed by questions evaluating the user's awareness of risks, understanding of difficulties, vigilance, and behavioural intentions in case of flood risk. This evaluation shows encouraging results, where the change of perspective does induce better awareness of risks, more protective actions intentions, and better vigilance and trust in the forecast. However, only very motivated users would answer the survey or play with the prototype, due to its boring and repetitive design. More work is needed to improve the game design and playability to make it more engaging (Brandtzaeg, Folstad, and Heim 2006), and allow it to be played by the general public and in particular by high school students. This is essential to guarantee that this serious game has an actual beneficial impact during future flood events. We are working with high school teachers to use our serious games in their courses about natural hazards.

The underlying population model can also be turned into an interactive simulator to train weather forecasters to apply crisis communication principles, and to take the subjective reactions of the population into account when announcing a forecast. This alternative version of Vigiflood is also under work in collaboration with Meteo France and the national school of meteorology. At a time when more and more floods are expected to happen in some parts of the world (Roudier et al. 2016; Kerr 2007; Schiermeier 2011), we believe that agent-based simulation can provide very useful tools to train and educate both the population and the deciders in order to reduce impact of these floods.

\section{ACKNOWLEDGEMENTS}

This work is supported by the French National Research Agency in the framework of the Investissements d'Avenir program (ANR-15-IDEX-02), project Risk@UGA.

\section{REFERENCES}

Abt, C. C. (1970). Serious games. New York: Viking Press, 1970.

Adam, C., and Andonoff, E. (2019). "Vigi Flood: a serious game for understanding the challenges of flood risk communication”. In: ISCRAM. Valencia, Spain, May 2019.

Arnaud M., Adam, C., and Dugdale, J. (2017). "The role of cognitive biases in reactions to bushfires". In: ISCRAM, Albi. 2017.

Adam, C., and Bailly, C. (2019). "Communication During Bushfires, Towards a Serious Game for a Serious Matter”. In: International Journal of Information Systems for Crisis Response and Management (IJISCRAM) 10(2). Ed. by Banuls Silvera. 
Adam, C., and Dugdale J. (2018). "Agent-based analysis of the spread of awareness in the population in the prodromal phase of bushfires". In: Proceedings of the 51st Hawaii International Conference on System Sciences.

Adam, C., and Gaudou, B. (2016). "Modelling human behaviours in disasters from interviews: application to Melbourne bushfires”. In: Social Simulation Conference (SSC).

Arru, M., Negre, E., and Rosenthal-Sabroux, C. (2019) "To alert or not to alert? That is the question”. In: HICSS-52. pp. 649-658.

Arvai, L. J. (2003). "Using risk communication to disclose the outcome of a participatory decision-making process: Effects on the perceived acceptability of risk-policy decisions". Risk Analysis: An International Journal, 23(2), pp. 281-289.

Attansey, M. I. (2012). "Vigilance versus Complacency: Communication Strategies Used During Fargo's Recent Major Floods to Confront Risk Fatigue”. PhD thesis. North Dakota State University.

Axelrod, R. (1997). "Advancing the Art of Simulation in the Social Sciences". Simulating social phenomena. Lecture Notes in Economics and Mathematical Systems, volume 456. Springer, pp. 21-40. https://link.springer.com/chapter/10.1007/978-3-662-03366-1_2

Bañgate, J., et al. (2017). “A Review on the Influence of Social Attachment on Human Mobility During Crises”. ISCRAM. Albi.

Barreto, P. A. C. (2014). "Treme-treme - A serious game to teach children earthquake preparedness". Master thesis. Portugal: Tecnico Lisboa, Nov. 2014. https:// fenix. tecnico.ulisboa.pt/downloadFile/563345090413387/dissertacao.pdf.

Becu N., et al. (2017). "Participatory simulation to foster social learning on coastal flooding prevention”. In : Environmental modelling \& software 98, pp. 1-11.

Becu N. (2020). "Les courants d'influence et la pratique de la simulation participative : contours, design et contributions aux changements sociétaux et organisationnels dans les territoires." (Practices of participatory simulation: contribution to societal changes in territories). (in French) Habilitation à Diriger des Recherches. PhD thesis. La Rochelle Université, 2020. https://collaboratif.cirad.fr/alfresco/s/d/workspace/SpacesStore/b183e2afc1cc-474a-b301-aa57af816622/Becu_2020_HDR.pdf.

Behrens, J., et al. (2008). "HANDLING UNCERTAINTY IN TSUNAMI EARLY WARNING: INTERACTION BETWEEN DECISION SUPPORT AND MULTI-SENSOR SIMULATION SYSTEM”. International Conference on Tsunami Warning (ICTW).

Bonabeau, E. (2002), “Agent-based modeling: methods and techniques for simulating human systems". Proceedings of the National Academy of Sciences, 99(3), pp. 7280-7287. 
Bottino M. R., Ott, M. and Tavella, M. (2014). "Serious Gaming at School: Reflections on Students' Performance, Engagement and Motivation”. International Journal of Game-Based Learning (IJGBL), 4(1), pp. 21-36. https://hal.archives-ouvertes.fr/ hal00984380/document.

Bowman, L. S. (2010). The Functions of Role-Playing Games: How Participants Create Community, Solve Problems and Explore Identity. McFarland \& Company.

Bowman, L. S. (2014). “Educational Live Action Role-playing Games: A Secondary Literature Review". The Wyrd Con Companion Book, pp. 112-131.

Boyle, A. E., et al. (2016). "An update to the systematic literature review of empirical evidence of the impacts and outcomes of computer games and serious games". Computers and Education, 94, pp. 178-192.

Brandtzaeg, B, P., Følstad, A., and Heim, J. (2006). "Enjoyment: Lessons from Karasek". In: Funology: From Usability to Enjoyment. Ed. by M.A. Blythe et al. Vol. 3. Human-Computer Interaction. Netherlands: Springer, pp. 55-65. https://link.springer.com/chapter/10.1007/14020-2967-5_6.

Burke, W. J., et al (2009). "Optimising engagement for stroke rehabilitation using serious games". The Visual Computer, 25(12), p. 1085.

Burningham K., Fielding, J., and Thrush, D. (2008). “'It'll never happen to me': understanding public awareness of local flood risk". Disasters, 32(2), pp. 216-238.

CEPRI (2008). Prévision et anticipation des crues et des inondations. (Prediction and anticipation of floods.) (in French) Tech. rep. Paris, France: Centre Europeén de Prévention du Risque Inondation, 2008.

https://www.cepri.net/tl_files/Guides\%20CEPRI/Guide_Prevision_Crues_BD.pdf

Covello T. V. (2003). "Best Practices in Public Health Risk and Crisis Communication". Journal of Health Communication, 8(1), pp. 5-8.

Covello, V. and Sandman P. M. (2001). "Risk communication: Evolution and Revolution". Solutions to an Environment in Peril, pp. 164-178.

CRED Center for Research on the Epidemiology of Disasters. The International Disaster Database. https://www.emdat.be/.

Daupras, F., et al. (2015). "Analysis of the robustness of the French flood warning system: a study based on the 2009 flood of the Garonne River". Natural Hazards, 75(1), pp. 215-241.

De Boer, J., Botzen, W. J. W., and Terpstra, T. (2014). "Improving Flood Risk Communication by Focusing on Prevention-Focused Motivation”. Risk analysis, 34(2), pp. 309-322.

Degrace. J-N. and Honore, C. (2010). The Vigilance system in France (continental and overseas): An example of an Early Warning System with a Multi-Hazard Approach. 
Djaouti, D., et al. (2011). "Origins of Serious Games". Serious Games and Edutainment Applications. Springer, pp. 25-43.

Di Loreto, I., Mora, S., and Divitini, M. (2012). "Collaborative Serious Games for Crisis Management: An Overview". In: Workshop on Enabling Technologies: Infrastructure for Collaborative Enterprises. IEEE. DOI: 10.1109/WETICE.2012.25.

Douglas, M., and Wildavsky, A. (1983). Risk and culture. Berkeley: University of California Press.

Duan, W., He, B., Kaoru Takara, et al. (2014). "Anomalous atmospheric events leading to Kyushu's flash floods, July 11-14, 2012”. Natural Hazards, 73(3), pp. 1255-1267.

Duan, W., He, B., Nover, D., et al. (2016). "Floods and associated socioeconomic damages in China over the last century". Natural Hazards, 82(1), pp. 401-413.

Eiser, J. R. (1998) “Communication and interpretation of risk”. British medical bulletin, 54 (4), pp. 779-790. https://academic.oup.com/bmb/article/54/4/779/323616

European Commission. The EU Floods Directive: Floods and their impacts. 2019. https://ec.europa.eu/environment/water/flood_risk/impacts.htm.

Fanta, V., Šálek, M., and Sklenicka, P. (2019). "How long do floods throughout the millennium remain in the collective memory?" Nature communications, 10(1), p. 1105.

Fire Services Commissioner (2013). Review of the community response in recent bushfires. Tech. rep. NOUS group. https://files-em.em.vic.gov.au/public/EMV-web/Review-ofcommunity-response-to-bushfire-executive-summary.pdf

Fitzgerald, J. et al. (2000). "Education and Young People-Forces for Change?" Australian Journal of Emergency Management, 15(3), p. 1.

Floyd, D. L., Prentice-Dunn S., and Rogers, R. W. (2000). “A Meta-Analysis of Research on Protection Motivation Theory”. Journal of Applied Social Psychology, 30(2), pp. 407-429.

Friedemann, M., et al. (2011). "Explicit modeling and visualization of imperfect information in the context of decision support for tsunami early warning in Indonesia". In: Symposium on Human Interface. Springer, pp. 201-210.

Garris, R., Ahlers, R., and Driskell, E. J. (2002). "Games, Motivation, and Learning: A Research and Practice Model”. Simulation \& Gaming, 33(4), pp. 441-467.

Geleta, B. (2013). Community early warning systems: guiding principles. Tech. rep. International Federation of Red Cross (IFRC). https://www.ifrc.org/PageFiles/103323/1227800-IFRC-CEWS-Guiding-Principles-EN.pdf

Gominet, S. (2018). “Inondations dans l'Aude d'octobre 2018: réflexions autour d'une vigilance rouge décrite comme trop tardive (in French) [Floods in Aude in October 2018: thoughts around a red vigilance described as too late]". Actualités de l'Institut des Risques 
Majeurs (2018). Accessed 14 October 2020. http://www.irmagrenoble.com/01actualite/01articles_afficher.php?id_actualite=694

Grothmann, T. and Reusswig, F. (2006). "People at Risk of Flooding: Why Some Residents Take Precautionary Action While Others Do Not”. Natural hazards, 38(1-2), pp. 101-120.

Guha-Sapir, D. (2018). Natural Disasters 2018. Tech. rep. Brussels: Centre for Research on the Epidemiology of Disasters, UC Louvain, 2019. https://reliefweb.int/sites/reliefweb.int/files/resources/CREDNaturalDisaster2018.pdf.

Haer, T., Wouter Botzen, J. W., and Aerts, C. J. H. J (2016). “The effectiveness of flood risk communication strategies and the influence of social networks. Insights from an agent-based model". Environmental Science and Policy, 60, pp. 44-52.

Harries, T. (2008). "Feeling secure or being secure? Why it can seem better not to protect yourself against a natural hazard”. Health, risk and society, 10(5), pp. 479-490.

Höppner, C., et al. (2012). "Linking social capacities and risk communication in Europe: a gap between theory and practice?" Natural hazards, 64(2), pp. 1753-1778.

Horita, A. F. E., et al. (2014). "A Gamification-based Social Collaborative Architecture to increase resilience against natural disasters". Anais do X Simpósio Brasileiro de Sistemas de Informação. SBC., pp. 399-410.

Hurnen, F. and McClure, J. (1997). "The Effect of Increased Earthquake Knowledge on Perceived Preventability of Earthquake Damage”. In: Australasian Journal of Disaster and Trauma Studies. 1997-3. http://trauma.massey.ac.nz/issues/1997-3/mcclure1.htm.

Izadkhah, O. Y., and Hosseini, M. (2005). "Towards resilient communities in developing countries through education of children for disaster preparedness". International journal of emergency management, 2(3), pp. 138-148.

J. J. Infanti, et al. (2013). A literature review on effective risk communication for the prevention and control of communicable diseases in Europe. Tech. rep. Stockholm: European Centre for Disease Prevention and Control. https://www.ecdc.europa.eu/sites/portal/files/media/en/publications/Publications/riskcommunication-literary-review-jan-2013.pdf.

Johnson, B.B., and Covello, V.T. (1987). The social and cultural construction of risk: Essays on risk selection and perception. Vol. 3. Dordrecht: Reidel, 1987.

Kerr, A. R. (2007). “Global warming is changing the world”. Science, 316(5822) pp. 188-190.

Khan, S., Crozier, J. M, and Kennedy, D. (2012). "Influences of place characteristics on hazards, perception and response: a case study of the hazardscape of the Wellington Region, New Zealand". Natural Hazards, 62(2), pp. 501-529. 
Le Monde. (2018). Inondations dans l'Aude : quelle est l'efficacité du système d'alerte météo ? [Floods in Aude: how efficient is the weather alert system?] (17 Octobre 2018). https://www.lemonde.fr/les-decodeurs/article/2018/10/17/inondations-dans-l-aude-quelleest-1-efficacite-du-systeme-d-alerte-meteo_5370643_4355770.html.

Libération-AFP. (2018). “Aude, 12 morts dans les inondations : la vigilance rouge déclenchée trop tard ? (in French) [Aude, 12 dead in the floods: the red vigilance triggered too late?]" Libération (15 October 2018). https://www.liberation.fr/france/2018/10/15/12-morts-dansles-inondations-la-vigilance-rouge-declenchee-trop-tard_1685368

Maidl, E., and Buchecker, M. (2015). "Raising risk preparedness by flood risk communication." Natural Hazards and Earth System Sciences, 15(7).

Murakami, Y., et al. (2002). "Multi-agent simulation for crisis management". Proceedings. IEEE Workshop on Knowledge Media Networking. IEEE. pp. 135-139.

Murata, A., Nakamura, T., and Karwowski, W. (2015) "Influence of cognitive biases in distorting decision making and leading to critical unfavorable incidents". Safety, 1(1), pp. 44-58.

Neuwirth, K., Dunwoody, S., and Griffin, R. (2002). "Protection Motivation and Risk Communication”. Risk Analysis, 20(5), pp. 721-734.

Paprotny, D., et al, (2018). "Trends in flood losses in Europe over the past 150 years". Nature communications, 9, 1985 (2018), pp.1-12.

Parker, J. D., Priest, J. S., and Tapsell, M. S. (2009). "Understanding and enhancing the public's behavioural response to flood warning information". Meteorological Applications: A journal of forecasting, practical applications, training techniques and modelling, 16(1), pp. 103-114.

Pearson, L. (2012). Early warning of disasters: Facts and figures. Tech. rep. Sci Dev Net. https://www.scidev.net/global/earth-science/feature/early-warning-of-disasters-facts-andfigures-1.html.

Reynolds, B. (2010). "Principles to enable leaders to navigate the harsh realities of crisis and risk communication". Journal of Business Continuity \& Emergency Planning, 4(3), pp. 262273.

Reynolds, B. and Seeger, M. (2014). Psychology of a crisis. Tech. rep. US department of health, human services. Center for disease control, and prevention. https://emergency.cdc.gov/cerc/ppt/CERC_Psychology_of_a_Crisis.pdf.

Rhodes, A. (2014). "Why don't they do what we think they should?" In: AFAC. Emergency Management Victoria.

Roudier, P., et al. (2016). "Projections of future floods and hydrological droughts in Europe under a $+2{ }^{\circ} \mathrm{C}$ global warming”. Climatic change, $135(2)$, pp. 341-355. 
Samaddar, S., Misra, A. B., and Tatano, H. (2012). "Flood risk awareness and preparedness: The role of trust in information sources". 2012 IEEE International Conference on Systems, Man, and Cybernetics (SMC). IEEE. 2012, pp. 3099-3104.

Sandman, P. (2003). Beyond Panic Prevention: Addressing Emotion in Emergency Communication. Emergency risk communication. Centers for disease control, prevention, US dept of health, and human services.

https://www.orau.gov/hsc/ercwbt/content/ERCcdcynergy/Content/activeinformation/resour ces/BeyondPanicPrevention.pdf.

Schiermeier, Q. (2011). "Increased flood risk linked to global warming: likelihood of extreme rainfall may have been doubled by rising greenhouse-gas levels". Nature, 470, pp. 316-317.

Shubik, M. (1971). “On the Scope of Gaming”. Management Science, 18(5-2), https://doi.org/10.1287/mnsc. 18.5 .20

Siegrist, M. and Gutscher, H. (2008). "Natural hazards and motivation for mitigation behavior: people cannot predict the affect evoked by a severe flood". Risk Analysis, 28, pp. 771-778.

Slovic, P. (2016). "Perceived risk, trust and democracy". The perception of risk. Routledge, 2016.Chap. 19, pp. 316-326.

Svetlana, D., Radovan, D., and Ján D. (2015). “The Economic Impact of Floods and their Importance in Different Regions of the World with Emphasis on Europe”. Procedia Economics and Finance 34, pp. 649-655.

Taillandier, F. and Adam, C. (2018). "Games Ready to Use: A Serious Game for Teaching Natural Risk Management”. Simulation \& Gaming, 49(4), pp. 441-470.

Terpstra, T., Lindell, M., and Gutteling, J. (2009). "Does communicating (flood) risk affect (flood) risk perceptions? Results of a quasi-experimental study". Risk Analysis, 29(8), pp. $1141-1155$.

Terti, G. et al. (2019). “ANYCaRE: a role-playing game to investigate crisis decision-making and communication challenges in weather-related hazards". Natural Hazards and Earth System Sciences, 19(3), pp. 507-533.

Weinstein, N., et al (2000). "Preoccupation and affect as predictors of protective action following natural disaster”. British Journal Health Psychology, 5(4), pp. 351-363.

Yamori, K. (2012). "Using games in community disaster prevention exercises". Group Decision and Negotiation, 21(4) pp. 571-583.

Yang, E. L. (2018), et al. "Assessment of Flood Losses with Household Responses: AgentBased Simulation in an Urban Catchment Area". Envir. Modeling \&Assessmt, 23(4), pp. 369-88. 


\section{Annex1: list of questions (translated from French)}

- Phase 1: experience, awareness and trust

1. Have you experienced floods before?

2. Did these floods affect your residence?

3. Were these floods announced in advance?

4. Did these floods require your evacuation?

5. Do you know about Meteo France vigilance system?

6. Do you know about Vigicrues monitoring website?

7. Do you trust these meteorological forecasts in case of floods?

8. Do you trust the local authorities to warn and protect you in case of floods?

- Phase 2: awareness of risk, challenges, and self-responsibility; intended actions (BEFORE)

9. Who do you think is responsible for your information and protection in case of floods?

10. How easy/hard do you think it is to announce the right level of vigilance?

11. What information do you think the authorities rely on to set the vigilance level?

12. How important is it to be certain of a forecast before announcing a vigilance level to the population?

13. What is the minimal reliability required before announcing a level of vigilance?

14. In your opinion, what level of danger does an orange flood vigilance indicate?

15. In your opinion, what level of danger does a red flood vigilance indicate?

16. In case of orange/red flood vigilance, what do you do? (check all actions among: search information, share information, prepare house, gather with relatives, park car higher, evacuate, nothing special)

17. During the last 2 orange vigilances, there were no flood in the end. What is your reaction to the next orange vigilance? (trust it anyway, distrust it anyway, trust it more, trust it less)

- Phase 3: change of perspective, setting vigilance in different situations: 
18. Series of questions of the form: the weather forecast services announce XXX mm of rain with a confidence index of $\mathrm{XXX} \%$. Which vigilance colour do you wish to announce?

19. Series of similar questions with additional contextual elements

20. Series of similar questions with additional information about previous false alarms and population trust

- Phase 4: evaluating the game (rate on a 5-point scale):

21. Such a game would be interesting to play

22. Such a game would be boring and repetitive

23. Such a game would be useful to learn and understand the vigilance system

24. You would like your town council to offer such a game as part of its flood risk prevention plan

25. You would like schools to offer such a game to children as part of their program about natural hazards

- Phase 5: re-assessing awareness and intentions (AFTER):

26. Same questions as in phase 2

27. Have you discovered new criteria for the definition of the flood vigilance level that you had not considered before? If yes, which ones?

28. Free comments

- Phase 6: demographic questions: region of residence, age, gender, job (if related with weather forecast or depending on weather conditions) 